\title{
ANATOMIA DO LENHO DE DUAS ESPÉCIES SUL-BRASILEIRAS DO GÊNERO MIMOSA L. E SUBSÉRIE OBSTRIGOSAE (BENTH.) BARNEBY ${ }^{1}$
}

\author{
PAULO FERNANDO DOS SANTOS MACHADO² JOSÉ NEWTON CARDOSO MARCHIORI ${ }^{3}$
}

\section{RESUMO}

São microscopicamente descritos os lenhos de Mimosa parvipinna Benth. e Mimosa ramulosa Benth. Ambas as espécies apresentam porosidade difusa, placas de perfuração simples, pontoações arredondadas, alternas e ornamentadas, parênquima paratraqueal, fibras libriformes, cristais romboédricos no contato parênquima/ fibras e raios heterogêneos. Mimosa parvipinna separa-se facilmente de Mimosa ramulosa por ter raios mais estreitos e baixos em número de células.

Palavras-chave: Anatomia da madeira, Obstrigosae, Mimosa, Mimosa parvipinna, Mimosa ramulosa.

\section{ABSTRACT}

[Wood anatomy of two South Brazilian species from genus Mimosa L. and subseries Obstrigosae (Benth.) Barneby].

The woods of Mimosa parvipinna Benth. and Mimosa ramulosa Benth. are anatomically described. Both species show diffuse-porous wood, simple perforation plates, rounded, alternate and vestured pits, paratracheal parenchyma, libriform fibers, rhomboedral crystals in the contact axial parenchyma/fibers, and heterogeneous rays. Mimosa parvipinna can be distinguished from Mimosa ramulosa by having narrower and lower rays in number of cells.

Key words: Mimosa, Mimosa parvipinna, Mimosa ramulosa, Obstrigosae, Wood anatomy.

\section{INTRODUÇÃO}

Apesar das numerosas espécies nativas na flora lenhosa sul-brasileira, Mimosa L. (Fabaceae: Mimosoideae) é gênero ainda pouco conhecido no tocante à anatomia da madeira e segue à espera de uma abordagem estrutural mais ampla, com vistas ao reconhecimento de táxones infragenéricos. No caso da subsérie Obstrigosae (Benth.) Barneby, à qual se inserem as duas espécies presentemente descritas, essa lacuna mostra-se ainda mais evidente, visto dispor de escassas referências anatômicas, e para apenas uma de suas espécies.

1 Recebido em 13-2-2016 e aceito para publicação em 23-4-2016.

2 Engenheiro Florestal, doutorando do Programa de PósGraduação em Engenharia Florestal, Universidade Federal de Santa Maria, Santa Maria, RS, Brasil. barcasole@gmail.com

3 Engenheiro Florestal, Dr. Bolsista de Produtividade em Pesquisa (CNPq - Brasil). Professor Titular do Departamento de Ciências Florestais, Universidade Federal de Santa Maria.
Com a presente descrição microscópica dos lenhos de Mimosa parvipinna e Mimosa ramulosa dá-se início a uma linha de pesquisa mais ampla, com vistas a lograr o reconhecimento de caracteres anatômicos de valor diagnóstico para a subsérie taxonômica a que pertencem ambas as espécies.

\section{REVISÃO DE LITERATURA}

Com 536 espécies, em sua grande maioria do continente americano (Simon et al., 2011), o gênero Mimosa L. tem como principais centros de diversidade o Brasil central e a América do Sul extratropical, incluindo Argentina, Uruguai, Paraguai e Sul do Brasil (Barneby, 1991). Apesar da grande diversidade de habitats ocupados, a maioria de suas espécies é de formações abertas, salientando-se, além disso, a existência de numerosos endemismos (Simon \& Proença, 2000).

A partir de ancestrais Piptadenióides, Barneby (1991) trata inicialmente da seção Mimadenia em seu esquema filogenético, se- 
guida por Batocaulon, que teria dado origem às seções Calothamnos e Habbasia; a partir dessa última, por fim, ter-se-ia derivado a seção $M i$ mosa. Para cada uma dessas seções, o botânico anglo-americano reconhece distintas séries e subséries botânicas. No caso da seção Mimosa são três as séries por ele reconhecidas Myriophyhllae, Modestae e Mimosa - sendo que esta última abrange a subsérie Obstrigosae (Benth.) Barneby, a qual pertencem as duas espécies em estudo.

Composto de dez espécies de arbustos e subarbustos lenhosos (Barneby, 1991), a subsérie Obstrigosae é facilmente reconhecida a campo pelas setas adpressas retrorsas, isto é, dirigidas para a base, tanto em ramos como em pedúnculos, bem como folhas unijugas e capítulos globosos axilares ou em racemos. Embora providas de acúleos, algumas espécies do grupo são inermes (Burkart, 1979) e, com exceção de Mimosa tandilensis e M. ourobrancoensis, as demais se encontram naturalmente no Rio Grande do Sul, de acordo com Barneby (1991).

Nativa em Missiones (Argentina), Paraguai, Uruguai e Rio Grande do Sul, Mimosa parvipinna Benth. é subarbusto inerme (sem acúleos), de folíolos glabros e estípulas triangular-lanceoladas, 3-5-nervadas (Izaguirre \& Beyhaut, 2003).

Subarbusto aculeado de até $2 \mathrm{~m}$ de altura, com pinas de até 18 pares de folíolos e legumes articulado-achatados, Mimosa ramulosa Benth. habita campos pedregosos e de baixa altitude, no Uruguai e Rio Grande do Sul (Izaguirre \& Beyhaut, 2003).

Com relação à anatomia do lenho, Cozzo (1951) refere ampla variação anatômica em Mimosa L., inexistindo uma característica peculiar ao gênero, comum a todas as espécies. Embora pouco investigado, devido ao pequeno porte da maioria de suas espécies e o escasso interesse econômico do lenho, a diversidade estrutural referida para o gênero corresponde ao descrito para toda a subfamília Mimosoideae (Cozzo, 1951).
Um das primeiras referências anatômicas deve-se a Record \& Hess (1949), autores que, baseados em Mimosa bracaatinga Hoehne (atual Mimosa scabrella Benth.) e Mimosa schomburgkii Benth. (espécie nativa da Guiana), atém-se, todavia, a caracteres gerais e organolépticos, não fazendo qualquer menção à estrutura microscópica do lenho. Metcalfe \& Chalk (1972) também não citam Mimosa L. em sua diagnose anatômica das Leguminosae Mimosaceae.

Em chave anatômica de 13 espécies argentinas, Domingo Cozzo relacionou os seguintes caracteres anatômicos para o gênero botânico: anéis de crescimento escassamente definidos, melhor demarcados em Mimosa ostenii; porosidade difusa, tendente a circular em $\mathrm{Mi}$ mosa ostenii, com arranjo dendrítico "bem notável" em M. hassleriana e M. uliginosa, e apenas com tendência a esse arranjo em $M$. cruenta e $M$. uruguensis; vasos solitários e em múltiplos de 2-3, menos comumente 4-5 poros, ou compondo longos múltiplos nas espécies com porosidade dendrítica; vasos de seção oval, angulares e de paredes delgadas em Mimosa pigra, espessas em $M$. polycarpa; elementos vasculares retilíneos ou levemente sinuosos, com placas de perfuração simples, oblíquas, e apêndices ausentes ou curtos, por vezes longos; pontoações intervasculares ornamentadas, pequenas a médias, alternas e quase sempre próximas entre si, embora não coalescentes; pontoações raiovasculares e parênquimo-vasculares, semelhantes às intervasculares; tilos e espessamentos espiralados geralmente ausentes, mas com espessamentos delgados em elementos muito curtos de Mimosa cruenta; traqueóides vasculares escassos, em espécies de porosidade dendrítica; raios heterogêneos a quase homogêneos, exclusivamente unisseriados em Mimosa pigra, predominantemente unisseriados em $M$. uruguensis, geralmente trisseriados em $M$. adpressa, e com raios multisseriados estreitos (até 5 células) em $M$. bimucronata e $M$. polycarpa; raios de até 50 células de altura $(80$ 
em M. adpressa), com células envolventes curtas, em poucas espécies, e células radiais oleosas em $M$. bimucronata; parênquima axial abundante em Mimosa cruenta, $M$. detinens e $M$. hassleriana, menos desenvolvido em $M$. adpressa, M. bimucronata e $M$. scabrella; células parenquimáticas axiais em séries e fusiformes, com predomínio de fusiformes em M. pigra; fibras libriformes muito curtas, de paredes finas a semi-espessas, frequentemente septadas, com fibrotraqueóides em Mimosa polycarpa (Cozzo, 1951); e estratificação do tipo incompleto, embora uniforme, em Mimosa adpressa e M. scabrella (Cozzo, 1948). Das espécies examinadas pelo anatomista argentino, apenas Mimosa adpressa insere-se na subsérie Obstrigosae (Benth.) Barneby.

Ao descrever a estrutura microscópica dos lenhos de Mimosa parvipinna e M. ramulosa, o presente estudo dá início a uma linha de pesquisa anatômica mais ampla, com vistas ao reconhecimento de eventuais caracteres diagnósticos para a subsérie Obstrigosae (Benth.) Barneby.

\section{MATERIAIS E MÉTODOS}

O material examinado consiste de amostras de madeira e exsicatas botânicas, conservadas na Xiloteca e Herbário do Departamento de Ciências Florestais da Universidade Federal de Santa Maria com os seguintes registros:

-HDCF 626. Mimosa ramulosa Benth. Leg.: Marchiori, J.N.C., 03-08-1982, Caçapava do Sul, arredores da cidade, às margens da BR; arbusto com cerca de $40 \mathrm{~cm}$ de altura, muito aculeado, com flores arroxeadas, estames brancos e estigma roxo.

- HDCF 769. Mimosa parvipinna Benth. Leg.: Marchiori, J.N.C., 21-10-1982, Santiago, RS, estrada para o Pilão d'água, próximo ao antigo aeroporto; campo seco.

Do material lenhoso foram preparados três corpos-de-prova $(1 \times 2 \times 3 \mathrm{~cm})$ de cada amostra de madeira, orientados para a obtenção de cortes anatômicos nos planos transversal, longitudinal radial e longitudinal tangencial; um quar- to corpo-de-prova foi também preparado, com vistas à maceração.

A confecção de lâminas de cortes anatômicos seguiu a metodologia descrita em Burger \& Richter (1991), usando-se, como corantes, uma mistura de Acridina-vermelha e Crisoidina, num primeiro banho, e Azul-de-Astra no segundo (Dujardin, 1964). No preparo de lâminas de macerado seguiu-se o método de Jeffrey (Freund, 1970), colorindo-se a pasta de fibras apenas com Safranina. Com vistas à montagem de lâminas permanentes, usou-se Entellan.

As descrições basearam-se nas recomendações da IAWA (Wheeler et al., 1989). No caso da percentagem dos tecidos foram realizadas 600 determinações ao acaso, com auxílio de contador de laboratório, conforme proposto por Marchiori (1980). A frequência de poros foi obtida a partir de um quadrado de área conheci$\mathrm{da}$, superposto a fotomicrografias em diferentes pontos de seções transversais da madeira.

As medições da estrutura anatômica foram realizadas em microscópio Carl Zeiss, no Laboratório de Anatomia da Madeira da Universidade Federal de Santa Maria. As imagens que ilustram o texto foram tomadas em fotomicroscópio Leica DM 1000, equipado com câmera digital Olympus Camedia CX 40, no Laboratório de Anatomia da Madeira do Centro de Educação Superior Norte do Rio Grande do Sul (CESNORS - UFSM), em Frederico Westfalen, RS. Nas características quantitativas, os números entre parênteses equivalem aos valores mínimos e máximos observados; o valor que acompanha a média é o desvio padrão.

\section{DESCRIÇÃO DAS ESPÉCIES}

\section{Mimosa parvipinna Benth.}

Anéis de crescimento: indistintos.

Vasos: extremamente numerosos $(104 \pm 21$ (65-165 poros $/ \mathrm{mm}^{2}$ ), ocupando $8 \pm 2,6 \%$ do volume da madeira. Porosidade difusa. Poros solitários (22\%), em múltiplos radiais de 2-9 (70\%), em múltiplos racemiformes de 3-5 (5\%) e em múltiplos tangenciais de 2-6 (3\%); circulares ou ovais $(30 \pm 10(2-50) \mu \mathrm{m})$ e de paredes 
finas a espessas $(3 \pm 1,2(0,8-5) \mu \mathrm{m})$ (Figura $1 \mathrm{~A}, \mathrm{~B})$. Elementos vasculares curtos $(138 \pm 31$ (80-200) $\mu \mathrm{m})$, com placas de perfuração simples, oblíquas ou transversais ao vaso; geralmente sem apêndices. Pontoações intervasculares pequenas e arredondadas $(5,8 \pm 0,6(5,2-7,2)$ $\mu \mathrm{m})$, alternas, ornamentadas, com abertura em fenda inclusa, por vezes coalescente (Figura 1F). Pontoações raio-vasculares, semelhantes às intervasculares, embora menores $(4,9 \pm 0,8(3,6$ $6,2) \mu \mathrm{m})$. Espessamentos espiralados, ausentes. Conteúdos, presentes.

Parênquima axial: representando $15 \pm 3,7 \%$ do volume da madeira; paratraqueal vasicêntrico, por vezes unilateral e em faixas tangenciais que atravessam vários raios, simulando limite de anel de crescimento. Conteúdos, escassos (Figura 1A, B). Células fusiformes de $178 \pm 21(150-225) \mu \mathrm{m}$ de altura. Séries parenquimáticas de $217 \pm 48$ (175-417) $\mu \mathrm{m}$ de altura, com $2 \pm 0,6$ (2-4) células (Figura 1F). Cristais romboédricos abundantes, em séries de 4-27 câmaras, dispostas, sobretudo, no contato com fibras (Figura 1C, D).

Raios: muito numerosos (13 \pm 2 (8-16) raios $/ \mathrm{mm}$ ), ocupando $31 \pm 5 \%$ do volume da madeira; estreitos (35 $\pm 3(28-40) \mu \mathrm{m})$ e heterogêneos, compostos de células quadradas e procumbentes (Figura 1C, D). Os unisseriados, predominantes $(55 \%)$, de $187 \pm 41$ (110-263) $\mu \mathrm{m}$ e 2-7 células de altura. Os multisseriados, em sua maioria bisseriados (42\%), menos comumente tri e tetrasseriados (3\%); de $416 \pm$ 129 (230-668) um) e 9-29 células de altura (Figura $1 \mathrm{E}, \mathrm{F})$. Células radiais de contorno arredondado ou poligonal, em plano tangencial. Raios fusionados e conteúdos, presentes; células envolventes, células radiais de paredes disjuntas e células perfuradas, ausentes.

Fibras: libriformes, não septadas, de $1023 \pm$ 211 (620-1420) $\mu \mathrm{m}$ de comprimento, com 14 $\pm 3,6(7,5-21) \mu \mathrm{m}$ de largura, e paredes finas a espessas $(3,8 \pm 1,3(1,3-6,3) \mu \mathrm{m}$, ocupando 46 $\pm 3 \%$ do volume da madeira (Figura 1B). Fibras gelatinosas, presentes; espessamentos espiralados, fibras septadas e traqueídeos, ausentes.

Outros caracteres: variantes cambiais, tubos laticíferos e taniníferos, canais intercelulares, células oleíferas, células mucilaginosas, estratificação e máculas medulares, ausentes.

\section{Mimosa ramulosa Benth.}

Anéis de crescimento: indistintos.

Vasos: muito numerosos (93 \pm 20 (64-135) poros $/ \mathrm{mm}^{2}$ ), ocupando $20 \pm 4,8 \%$ do volume da madeira. Porosidade difusa. Poros solitários (45\%), em múltiplos radiais de 2-7 (43\%), em múltiplos racemiformes de 2-5 (9\%) e em múltiplos tangenciais de 2-6 (3\%); circulares ou ovais $(53 \pm 13(25-80) \mu \mathrm{m})$ e de paredes finas a espessas $(4,7 \pm 1,2(2,5-6,3) \mu \mathrm{m})$ (Figura 2A,B). Elementos vasculares curtos $(257 \pm 60$ (120350) $\mu \mathrm{m}$ ), com placas de perfuração simples, oblíquas ou transversais ao vaso, e apêndices curtos $(18 \pm 9,6(10-30) \mu \mathrm{m})$, geralmente em uma extremidade. Pontoações intervasculares pequenas e arredondadas $(4,8 \pm 0,6(3,1-5,2)$ $\mu \mathrm{m})$, alternas, ornamentadas, com abertura em fenda inclusa, por vezes coalescente (Figura 2F). Pontoações raio-vasculares, semelhantes às inter vasculares, embora menores $(3,7 \pm 0,8(3,1-5,2)$ $\mu \mathrm{m})$. Conteúdos, presentes; espessamentos espiralados, ausentes.

Parênquima axial: representando $6 \pm 2,1 \%$ do volume da madeira; paratraqueal unilateral e apotraqueal-difuso, menos comumente vasicêntrico. Conteúdos, escassos (Figura 2A, B). Células fusiformes de $248 \pm 35$ (175-313) $\mu \mathrm{m}$ de altura. Séries parenquimáticas de $238 \pm$ 22 (188-263) $\mu \mathrm{m}$ de altura, com de 2 a 3 células por série (Figura 2F). Cristais romboédricos em séries de 2-10 câmaras, concentradas, sobretudo, no contato com o tecido fibroso.

Raios: numerosos ( $8 \pm 2$ (7-16) raios/mm), ocupando $19 \pm 4 \%$ do volume da madeira; estreitos (34 \pm 7 (25-50) $\mu \mathrm{m})$ e heterogêneos, compostos de células procumbentes e quadradas (Figura 2C, D). Os unisseriados (13\%), de 142 $\pm 55(63-238) \mu \mathrm{m}$ e $3-10$ células de altura. Os 

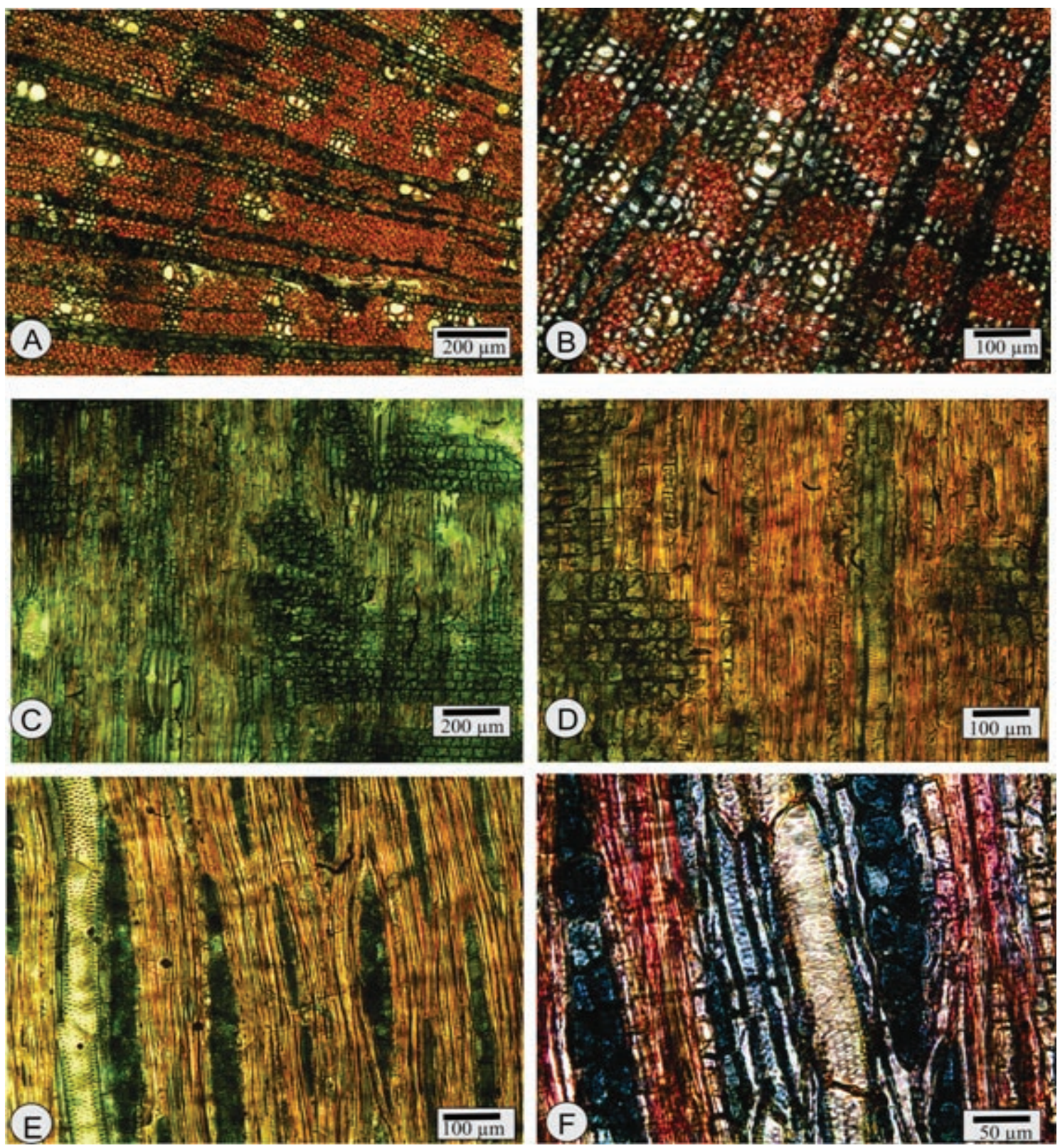

FIGURA 1 - Fotomicrografias do lenho de Mimosa parvipinna. A - Porosidade difusa, poros solitários e em múltiplos radiais, parênquima paratraqueal vasicêntrico e escasso, por vezes unilateral e em faixas tangenciais atravessando vários raios (seção transversal). B - Mesma seção; poros em múltiplos radiais e parênquima paratraqueal vasicêntrico. C - Raios heterogêneos compostos de células quadradas e procumbentes, e parênquima axial seriado (seção radial). D - Elementos vasculares com placas de perfuração simples (seção radial). E - Raios uni e bisseriados, e parênquima paratraqueal (seção tangencial). F - Elemento vascular com placas de perfuração simples, pontoações intervasculares ornamentadas, por vezes coalescentes, raios uni e bisseriados, e parênquima axial com cristais (seção tangencial). 

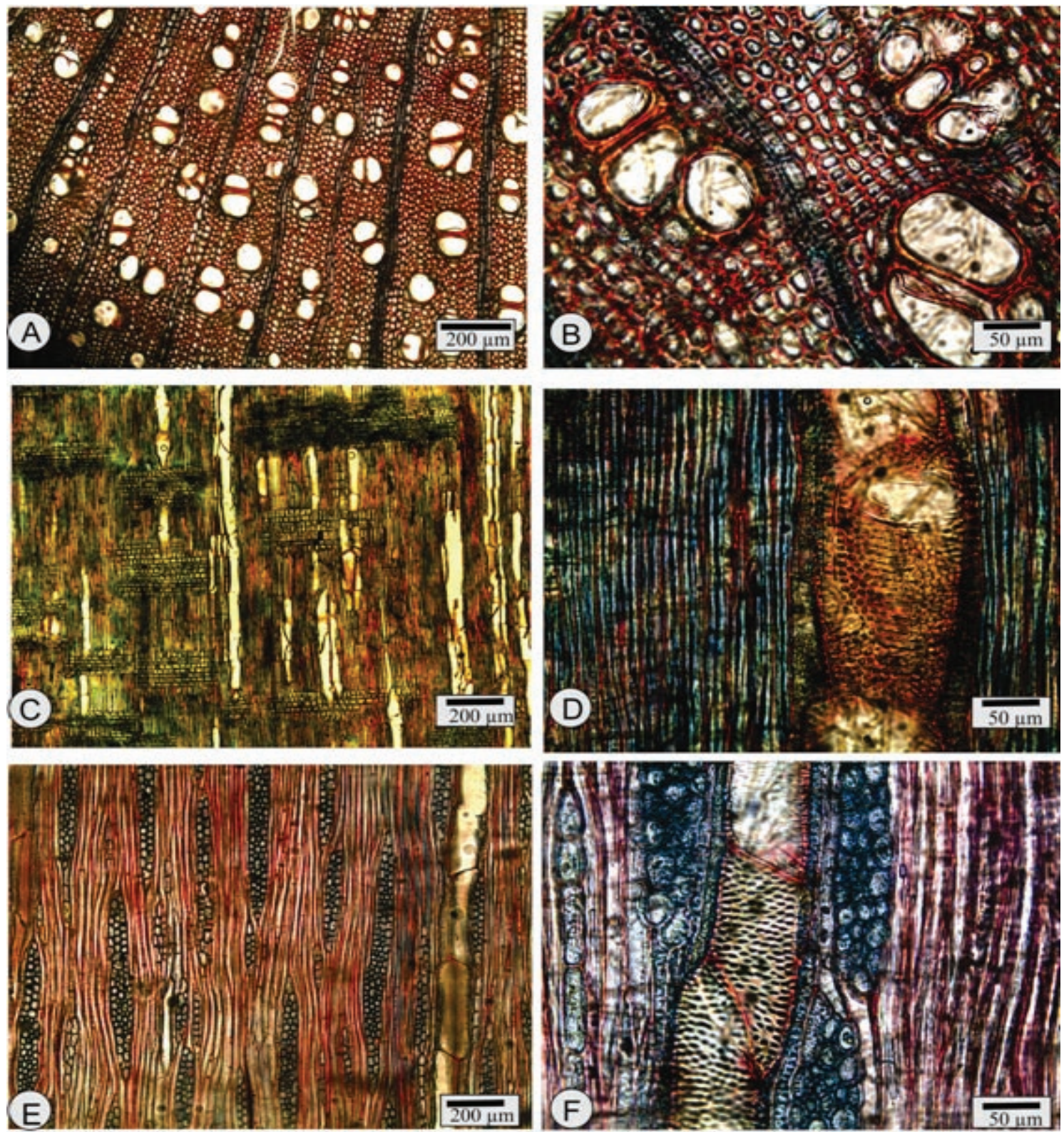

Figura 2 - Fotomicrografias do lenho de Mimosa ramulosa. A - Porosidade difusa, poros solitários e em múltiplos radiais, parênquima unilateral, por vezes vasicêntrico, e apotraqueal difuso (seção transversal). B - Detalhe de poros e parênquima paratraqueal (seção transversal). C - Raios heterogêneos, compostos de células procumbentes e quadradas, e elementos vasculares (seção radial). D - Mesmo plano, destacando elementos vasculares e parênquima axial seriado. E - Raios multisseriados e parênquima axial (seção tangencial). F - Elemento vascular com pontuações alternas ornamentadas, e raios estreitos (seção tangencial). 
multisseriados, em sua maioria trisseriados (42\%) e bisseriados (38\%), com escassos tetrasseriados (7\%); de $338 \pm 168$ (125-787) $\mu \mathrm{m}$ e 7-45 células de altura (Figura 2E, F). Raios fusionados e conteúdos, presentes. Células radiais de contorno arredondado ou poligonal, em plano tangencial (Figura 2F). Células envolventes, células radiais de paredes disjuntas e células perfuradas, ausentes.

Fibras: libriformes, de $724 \pm 107$ (550-950) $\mu \mathrm{m}$ de comprimento, com $16 \pm 1,9$ (12-20) $\mu \mathrm{m}$ de largura, e paredes finas a espessas $(3,4 \pm 0,7$ $(1,8-5) \mu \mathrm{m})$, ocupando $55 \pm 3,8 \%$ do volume da madeira (Figura 2B). Fibras gelatinosas, presentes; espessamentos espiralados, fibras septadas e traqueídeos, ausentes.

Outros caracteres: variantes cambiais, tubos laticíferos e taniníferos, canais intercelulares, células oleíferas, células mucilaginosas, estratificação e máculas medulares, ausentes.

\section{ANÁLISE DA ESTRUTURA ANATÔMICA}

Os lenhos de Mimosa parvipinna e M. ramulosa apresentam numerosos caracteres anatômicos em comum, salientando-se: porosidade difusa; placas de perfuração simples; pontoações arredondadas, alternas e ornamentadas; parênquima paratraqueal; fibras libriformes; cristais romboédricos, sobretudo no contato do parênquima axial com fibras; e raios heterogêneos. O último caráter, todavia, não é comum em Mimosaceae, mas sim de Caesalpiniaceae e Papilionaceae, segundo Metcalfe \& Chalk (1972), autores que distinguem Mimosaceae por terem os raios mais especializados das Leguminosae.

Com relação a esse ponto, Baretta-Kuipers (1981) concluiu, com base em estudo de 35 gêneros de Mimosoideae, 85 de Caesalpinioideae e 68 de Papilionoideae, que a homogeneidade dos raios é caráter importante para a taxonomia da madeira em Leguminosae, e que Caesalpinioideae apresenta a estrutura menos evoluída da família. Segundo a autora, esta subfamília constitui a base, a partir da qual a especialização anatômica progrediu em dois rumos distintos: em direção às Mimosoideae, com a especialização dos raios, e em direção às Papilionoideae, com a estratificação de todos os elementos. É interessante notar que Burkart (1952) chegou, praticamente, à mesma conclusão, com base na morfologia externa.

A heterogeneidade dos raios, observada tanto em Mimosa parvipinna como em $M$. ramulosa, é, portanto, caráter atípico ou incomum em Mimosaceae e, por consequiência, de valor diagnóstico para a identificação de espécies ou de eventuais grupos infragenéricos, tema a ser esclarecido por pesquisas mais abrangentes no futuro, incluindo maior número de binômios.

Em estudo de madeiras sul-americanas de Leguminosae (Fabaceae), Reinders-Gouwentak (1955) observou que a presença de estratificação permite dividir a família em dois grupos Mimosaceae e Papilionaceae -, o último dos quais incluindo Caesalpinioideae, com base na presença frequente do caráter no grupo. A ausência de estratificação em Mimosa parvipinna e $M$. ramulosa, comprovada na presente pesquisa, está de acordo com essa generalização; cabe ressaltar, entretanto, que Cozzo (1948, 1951) refere o caráter para Mimosa adpressa, espécie da mesma subsérie botânica, aspecto que, apesar de contestar a tendência referida por Reinders-Gouwentak (1955), aumenta o valor diagnóstico do mesmo na identificação anatômica de espécies da subsérie Obstrigosae.

Baretta-Kuipers (1981) destaca a ocorrência de estratificação como caráter importante para o reconhecimento de tribos em Leguminosae, bem como o tipo de raios (homocelulares ou heterocelulares) e a largura dos mesmos (uni ou multisseriados); o arranjo do parênquima axial, segundo a mesma autora, mostra-se importante na segregação de gêneros e espécies.

Com relação à largura de raios, em Mimosa ramulosa predominam os trisseriados, à semelhança de M. adpressa (Cozzo, 1951), ao passo que em Mimosa parvipinna eles são mais finos, 
principalmente bisseriados. No tocante à altura, as duas espécies descritas apresentam raios mais baixos do que o referido por Cozzo (1951) para Mimosa adpressa (até 80 células), contribuindo para a segregação das mesmas na subsérie Obstrigosae; mesmo assim, ambas têm raios relativamente altos no gênero a que pertencem, chegando a 29 e 45 células de altura em Mimosa parvipinna e Mimosa ramulosa, respectivamente.

Em plano tangencial, o contorno arredondado ou poligonal das células radiais também merece comentário, uma vez que em outras espécies do gênero, tais como em Mimosa daleoides (Marchiori et al., 2011), observam-se células alongadas ou envolventes.

\section{REFERÊNCIAS BIBLIOGRÁFICAS}

BARETTA-KUIPERS, T. Wood anatomy of Leguminosae: its relevance to Taxonomy. In: POLHILL, R.M.; RAVEN, P.H. Advances in Legume Systematics. 1981. p. 677-715.

BARNEBY, R.C. Sensitive Censitae: A description of the genus Mimosa Linnaeus (Mimosaceae) in the New World. Memoirs of the New York Botanical Garden, v. 65, p. 1-835, 1991.

BURGER, L.M.; RICHTER, H.G. Anatomia da madeira. São Paulo: Ed. Nobel, 1991. 154p.

BURKART, A. Las Leguminosas argentinas silvestres y cultivadas. Buenos Aires: ACME Agency, 1952. 569 p.

BURKART, A. Leguminosas Mimosoideas. In: REITZ, R. Flora Ilustrada Catarinense. Itajaí: Herbário Barbosa Rodrigues, 1979. 299 p.

COZZO, D. Estructura leñosa estractrificada no registrada em géneros de Leguminosas argentinas. Lilloa, Tucumán, n. 16, p. 63-95, 1948.

COZZO, D. Anatomia del leño secundario de las Leguminosas Mimosoideas y Cesalpinoideas argentinas silvestres y cultivadas. Revista del Instituto Nacional de Investigación de las Ciencias Naturales, Ciencias Botánicas, Buenos Aires, v. 2, n. 2, p. 63-290, 1951.
DUJARDIN, E.P. Eine neue Holz-Zellulosenfaerbung. Mikrokosmos, n. 53, p. 94, 1964.

FREUND, H. Handbuch der Mikroskopie in der Technik. Frankfurt: Umsham Verlag, 1970. 375 p.

IZAGUIRRE, P.; BEYHAUT, R. Las Leguminosas en Uruguay y regiones vecinas. Parte 2. Caesalpinioideae. Parte 3. Mimosoideae. Montevideo: Hemisferio Sur, 2003. 302 p.

MARCHIORI, J.N.C. Estudo anatômico do xilema secundário e da casca de algumas espécies dos gêneros Acacia e Mimosa, nativas no estado do Rio Grande do Sul. Dissertação (Mestrado em Engenharia Florestal). Curitiba: Universidade Federal do Paraná, 1980. 186 f.

MARCHIORI, J.N.C., DENARDI, L., SANTOS, S.R. dos. Madeiras do Rio Grande do Sul. 3 Descrição microscópica de 34 espécies nativas. Santa Maria: Anaterra, 2011, p. 37.

METCALFE, C.R.; CHALK, L. Anatomy of the Dicotyledons. Oxford: Clarendon Press, 1972. $1500 \mathrm{p}$.

RECORD, S.J.; HESS, R.W. Timbers of the New World. New Haven: Yale University Press, 1949. $640 \mathrm{p}$.

REINDERS-GOUWENTAK, C.A. The storied structure features and the taxonomic rank of the leguminous taxa. Acta Botanica Neerlandica, n. 4, p. 460-470, 1955

SIMON, M.F., PROENÇA, C. Phytogeographic patterns of Mimosa (Mimosoideae, Leguminosae) in the Cerrado biome of Brazil: an indicator genus of high altitude centers of endemism? Biological conservation, n. 96, p. 276-296, 2000.

SIMON, M.F., QUEIROZ, R., SARKINEN, T.E., DUTRA, V.F.; HUGHES, C.E. The evolutionary history of Mimosa (Leguminosae): towards a phylogeny of the sensitive plants. American Journal of Botany, n. 98, p. 1201-1221, 2011.

WHEELER, E.A.; BAAS, P.; GASSON, P.E. IAWA list of microscopic features for hardwood identification. IAWA Bulletin, v. 10, n. 3, p. 218359, 1989. 